\title{
La Vicesecretaría de Educación Popular (1941-1945): un «ministerio» de la propaganda en manos de Falange
}

\author{
Benito Bermejo Sánchez *
}

"Los tradicionales partidos llamados revolucionarios nos han enseñado a través de una triste experiencia para España, de el poder sugestivo y casi hipnótico, que tiene sobre las colectividades lo que ellos llaman agitación.

La Falange, núcleo político que tiene la misión de revolucionar la vida de España, no puede prescindir de este arma poderosa que ya utilizó con resultados eficaces desde los albores de su nacimiento".

Federico de Urrutia (1941)

En el período comprendido entre la primavera de 1941 y el verano de 1945 funcionó en la España de Franco un organismo estatal que, con el nombre de Vicesecretaría de Educación Popular ${ }^{2}$, abarcó en su esfera de acción la práctica totalidad de los aspectos de la comunicación social, de cualquier forma de expresión pública, por medio de imágenes, textos, e incluso (sic) sonidos. Su fin era la propagación del modelo ideológico y

* (UNED).

- De un informe sobre la reorganización de la propaganda de Falange, sin fecha, pero correspondiente a un momento entre mayo y noviembre de 1941. Federico de Urrutia fue delegado provincial de Educación Popular en Madrid.

${ }^{2}$ En adelante, VSEP. 
cultural de FET y de las JONS, el cerrar el paso a la heterodoxia y, eventualmente, la represión del heterodoxo ${ }^{3}$.

Es al Partido único, a la propia Falange Española Tradicionalista y de las JONS, a quien incumbirá la tarea. La VSEP se hallaba, como parte del Partido, bajo la autoridad del ministro-secretario general del Movimiento y así siguió hasta que los aires que soplaban en 1945 parecieron aconsejar otra cosa y, en consecuencia, la estructura se transfirió entonces al Ministerio de Educación Nacional (pero con una muy directa dependencia real de Martín Artajo). Las líneas que siguen son un intento de análisis de aquel organismo, realizado principalmente a través de la documentación que generó ${ }^{4}$.

\section{CREACIÓN DEL ORGANISMO. CULMINACIÓN DE UN PROCESO DE CONCENTRACIÓN DE PODERES}

La creación de la VSEP implicó la asunción por parte de Falange de los poderes sobre el campo de la comunicación social o, más exactamente, de la acumulación, a las que ya detentaba el organismo que la precedia, de casi todas las competencias restantes. Ésto es resultado de dos procesos que discurren paralelos desde principios de la guerra civil ${ }^{5}$ : el creciente control estatal de este campo y la expansión del aparato falangista de propaganda.

Por un lado, el Estado fue estableciendo desde temprano una serie de organismos encargados del control y censura de la prensa, radio,

${ }^{3}$ Este trabajo recoge algunos aspectos tratados en una Tesis Doctoral en preparación (con la dirección del profesor Javier Tusell) en el Departamento de Historia Contemporánea de la UNED sobre la política de comunicación social del primer Franquismo. Sobre la Vicesecretaria de Educación Popular presentamos en 1989 una Tesis de Licenciatura en la Universidad de Salamanca (realizada con la dirección de la profesora Josefina Cuesta).

4 Esta documentación, procedente de modo inmediato del Ministerio de Información y Turismo, se halla actualmente en la Sección Cultura del Archivo General de la Administración, en Alcalá de Henares.

5 Una visión esquemática de la formación de los aparatos de propaganda del primer franquismo la intentamos ofrecer en "L'Espagne", en PESCHANSKI, Denis, y GERVEREAU, Laurent, La propagande sous Vichy. Paris, BDIC, 1990, págs. 263-271. Esta obra reúne un panorama muy amplio de los aspectos del Régimen de Vichy relacionados con la propaganda y la influencia sobre la opinión pública, además de trabajos sobre otros regímenes susceptibles de comparación como la Italia fascista, la Alemania hitleriana y la España de Franco, caso del trabajo del que esto escribe. 
cine, etc. Desde los gabinetes y oficinas de Salamanca (principalmente la Delegación de Estado para Prensa y Propaganda, que actúa durante el año 1937 y hasta su "revelo" de 1938) se fueron elaborando las primeras normas al respecto, a la vez que se controlaban todos los aspectos informativos, entonces directamente relacionados con la actividad bélica.

Por otra parte, Falange iba desarrollando su propio aparato de propaganda, dentro del que destacaba lo que se iba a convertir posiblemente en el mayor grupo periodístico (en número de cabeceras, si no en importancia real) de la historia de España, periódicos que "adquiere" en no pocas ocasiones mediante la incautación de fenecidos órganos republicanos, socialistas, etc., la absorción de algunos antiguos periódicos de derechas $o$, en algunos casos, la creación de otros nuevos ${ }^{6}$.

Con el primer Gobierno de Franco se produce la convergencia, en la persona de Serrano Suñer, de la autoridad del Estado en este campo (al depender de él como ministro de la Gobernación, los recién creados Servicios Nacionales de Prensa y Propaganda) y la del Partido, al ser Serrano a partir de ahora jefe nacional de Prensa y Propaganda de éste. Pero si en el campo de la propaganda (confiada a Ridruejo desde marzo de 1938) la unificación de ambas autoridades se hace pronto efectiva?, no será aún así en el ámbito de la prensa ${ }^{8}$. Para ésta se promulgó una ley que permaneció durante casi treinta años y que estableció las bases legales de la actuación (también de la VSEP) a su respecto ${ }^{9}$.

${ }^{6}$ Conocemos aún relativamente poco sobre la historia de la Cadena de Prensa que durante tantos años controló Falange. Estudios en profundidad, como la tesis en curso de Ricardo Martín de la Guardia (Universidad de Valladolid) sobre el diario Libertad, que no se limiten a un vaciado de los contenidos, van a suponer un necesario avance en el conocimiento de un aspecto realmente importante por su entidad y duración en el tiempo.

7 Muy pronto las Delegaciones de Propaganda del Partido y del Estado serán una sola, ubicada preferentemente en la jefatura del Partido.

${ }_{8}$ El esquema de organización que Jesús Timoteo Álvarez presenta en Historia de los medios de comunicación en España... Barcelona, Ariel, 1989, es adernás de incompleto, engañoso, ya que confunde las competencias de Estado y Partido. Por otro lado, de poco sirve afirmar tan rotundamente que "recuerda con precisión el esquema del Ministerio de Goebbels" (pág. 223) sin referirse a aspectos concretos, pues en igual o mayor medida recuerda a la estructura homóloga de la Italia coetánea; decir, por otro lado, que tiene "estructura piramidal» (ibid., op. cit.) no aclara demasiado.

${ }_{9}$ El autor inmediato de esta ley, el entonces jefe del Servicio Nacional de Prensa, José Antonio Giménez Arnau, trata en sus memorias (Giménez ARnau, José Antonio, Memorias de memoria. Barcelona, Destino, 1978) de presentarla como destinada a una situación de guerra y en modo alguno producto de una voluntad totalitaria. El propio análisis de la ley desmiente esas palabras, que no sorprenden en una obra donde domina la frivolidad, que le resta casi todo el valor documental. 


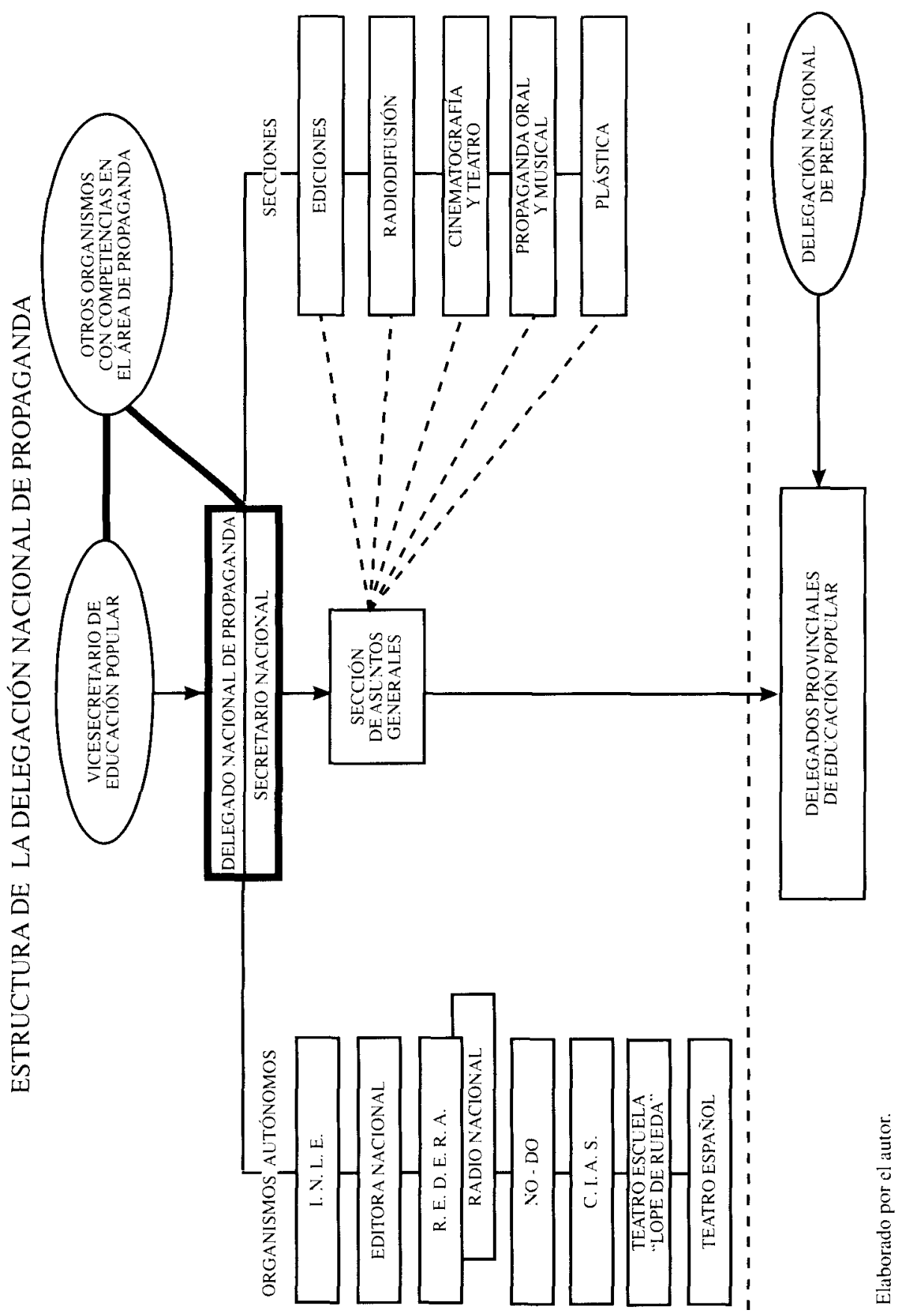




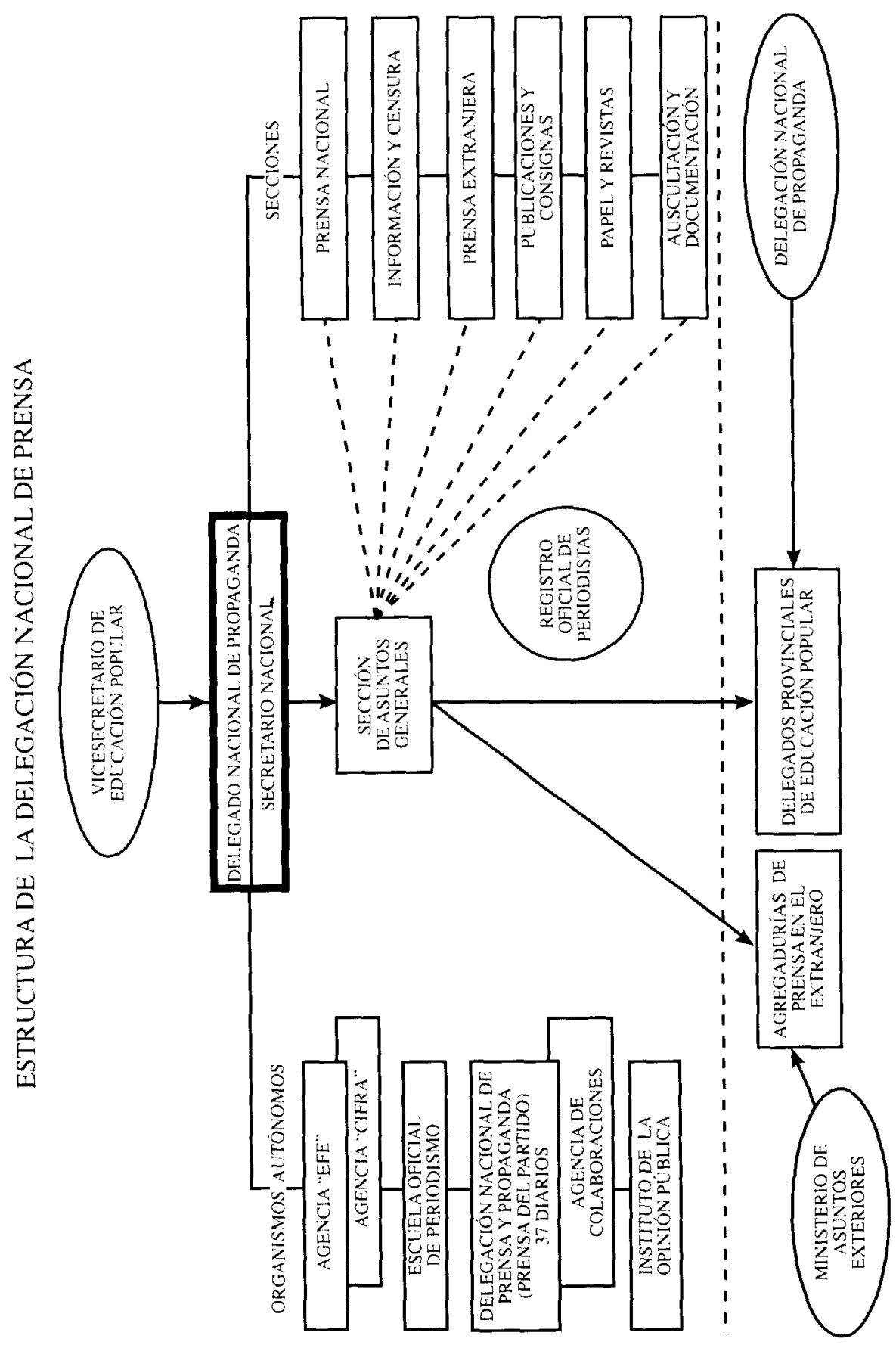


El 20 de mayo de 1941 se crea oficialmente la VSEP, señalándose en el texto que la crea explícitamente cómo está destinada a convertirse en Ministerio independiente aunque para esto último - se decia- no pareciese llegado el momento propicio ${ }^{10}$. Ciertas interpretaciones pretenden que la resolución de la crisis de mayo de 1941 (con el nombramiento para Gobernación del antifalangista Galarza, que derivó en crisis de Gobierno) supuso la pérdida por parte de Falange del control de la prensa. Este es el caso de Ricardo Chueca ${ }^{11}$, para el que esto quedaba probado por la orden de Galarza que anula la exención de la censura para la prensa falangista ${ }^{12}$. Se olvida lo muy coyuntural de tal orden, que se promulga en el momento de transición en que Galarza va a asumir la cartera de Gobernación pero en que la VSEP no está aún en marcha. Con la VSEP la censura de la prensa falangista irá quedando en manos de la propia Falange. Estas tesis sólo se pueden mantener desde una visión algo apriorística ${ }^{13}$, que quiere ver remontarse a fechas tan tempranas un proceso -el de pérdida de peso y significado de Falange - que sólo se afianza con la derrota del Eje en la Guerra Mundial; eso es ver 1945 en 1941, cuando las situaciones y sobre todo la visión de "lo previsible" variaron tanto de un momento a otro.

\section{ESTRUCTURA DE LA VSEP. LAS RAMIFICACIONES DE NUESTRA "FABRICA DEL CONSENSO" ${ }^{14}$}

La VSEP parece organizada según la estructura básica común al Partido, al subdividirse la Vicesecretaría en varias delegaciones naciona-

${ }^{10}$ Ello se puede deber, a nuestro juicio, a la intención de Franco de no alterar excesivamente en favor de Falange la relación de fuerzas en el seno del Gabinete Ministerial. Falange recibia así estas competencias, pero integradas bajo la autoridad de Arrese, como ministro-secretario general del Movimiento, lo que no impide que el titular de la VSEP, Arias Salgado, despachase de forma habitual directamente con Franco.

${ }^{11}$ CHUECA, Ricardo, "El fascismo en los comienzos del régimen de Franco. Un estudio de FET-JONS". Madrid, CIS, 1983, (Colección Monografías; 67), que trata estas cuestiones concretamente en págs. 276-294. Esta interpretación ha tenido bastantes seguidores, debido en parte al carácter en buena medida pionero que tuvo el trabajo de Chueca, lo que le añade un mérito que no le exime de las carencias que implicaba la falta de trabajo sobre fuentes primarias de archivo.

${ }^{12}$ La orden anulada es la del 4-5-1941, que exime de la censura a la Prensa de Falange.

${ }_{13}$ CHUECA, Ricardo, op. cit., en pág. 291, habla respecto a la VSEP de «la poca tendencia a servirse de los canales del Partido", lo que el análisis de documentación de ésta más bien desmiente, pues salvo excepciones existían unas relaciones directas con las delegaciones y servicios del Partido tanto en la central como las provincias y está bien fuera de dudas la relación directa con el jefe provincial de FET en cada provincia.

${ }^{14}$ La expresión procede de W. Cannistraro, Philipp, que en su obra "La fábrica del 
les, existir una serie de inspecciones, contar con sus delegados provinciales, etc. Teóricamente, los campos de cine y teatro y el de radio estaban destinados a corresponder a sendas Delegaciones Nacionales ${ }^{15}$, lo que no ocurrió en el periodo que nos ocupa, integrándose -a grandes rasgos - todo lo referente a prensa periódica en la Delegación Nacional de Prensa ${ }^{16}$ y el resto de las actividades en la Delegación Nacional de Propaganda ${ }^{17}$. Los cuadros adjuntos expresan gráficamente la estructura básica de ambas Delegaciones ${ }^{18}$.

Una novedad importante consiste en la unificación de la autoridad provincial para todas las competencias de la VSEP, que recaen en los delegados provinciales de Educación Popular, que paulatinamente sustituirán tanto a los antiguos delegados de Propaganda como a los jefes de Prensa responsables de la censura, hasta entonces ubicados estos últimos en los Gobiernos Civiles ${ }^{19}$. Están estos delegados investidos de una autoridad relativamente importante, sobre todo si se compara su situación a la de sus predecesores.

El escalón nacional de la VSEP comprende dos tipos de estructuras: las "Secciones", que abarcan la autoridad sobre un ramo de la producción cultural a la vez que la propia actividad propagandística del Partido y los "Organismos subvencionados" o autónomos, más limitados a aspectos concretos y en algunos casos auténticas "empresas" pertenecientes a la VSEP. Determinados organismos autónomos (caso del CIAS y la

consenso". Bari, Laterza, 1975 (Tempi Nuovi Laterza; 74) ofrece una historia del equivalente italiano de los organismos aqui estudiados, principalmente del Ministerio de Cultura Popolare.

${ }^{15}$ Así, en los fondos procedentes de la VSEP que se hallan en el Archivo General de la Administración, la documentación se encuentra en una división de delegaciones que en varios casos no existieron nunca, tal vez porque en la propia organización de los archivos de la VSEP se siguió la estructura legal y no la real.

${ }_{16}$ En adelante, DNPrensa.

17 En adelante, DNProp.

${ }_{18}$ Debido a lo cambiante de algunos aspectos de la organización no se refleja en los dos cuadros la totalidad de la estructura ni, sobre todo, su evolución. Pero creemos que aportan un elemento en claridad. Recordamos que las delegaciones provinciales de la VSEP dependian a la vez de la DNPrensa y la DNProp. Hubo alguna reorganización, como la que creó la Sección de Organización de Actos Públicos y Plástica.

${ }_{19}$ Este proceso se completa prácticamente a lo largo de todo el año 1942. Las modalidades en cuanto a la provisión del nuevo cargo son variadas: en algunas provincias será el antiguo delegado de Propaganda ahora responsable de la VSEP en la provincia; otras veces lo será el de Prensa y en el resto de los casos una persona ajena hasta el momento a esos cargos, en ocasiones formada en un curso ad hoc del que existieron dos promociones, en 1943 y 1944; vid. Boletín Oficial del Movimiento 2142, de 17-7-1943, con la convocatoria y el programa, que incluye materias de legislación relacionada con la VSEP, teoría de la propaganda, psicología de masas y "auscultación de la opinión pública", etc. 
Asociación Hispano-Germana) lo eran en virtud del interés del Régimen por que mantuvieran una apariencia de no-oficiales.

\section{La Delegación Nacional de Prensa}

Ocupada en la totalidad del período que nos ocupa por Juan Aparicio López, la DNPrensa tuvo en sus manos el control de la totalidad de las publicaciones periódicas nacionales o extranjeras (que entrasen en España), actividad que podria desglosarse en las siguientes prácticas:

- La depuración de los periodistas y el control de éstos y todos los trabajadores relacionados con estas actividades. Para ello se creó un Registro Central de periodistas y sólo mediante la admisión al mismo era posible ejercer como tal.

- El control de las empresas, con la potestad de autorizar la creación de otras nuevas, la posibilidad de imponerles un director y la potestad de poner en marcha un proceso de supresión de la publicación.

- La asignación de cupos de papel a las mismas (factor muy importante, indirectamente, de penalización o fomento de determinadas publicaciones).

- La censura previa de los textos, la inspección de los mismos ya publicados y la eventual sanción (a la publicación y/o al autor) de las infracciones.

- La retención y eventualmente eliminación de publicaciones enviadas desde el extranjero por correo, para lo que el brazo ejecutor eran los agentes de Censura Gubernativa establecidos en Correos.

- La consigna de prensa que podían suponer la imposición de ciertos textos, fotografías, etc., o de realizar comentarios de acuerdo con determinados guiones o bien de evitar tales o cuales temas o formas de tratarlos ${ }^{20}$.

20 Sobre la mayor parte de estas prácticas, pero especialmente sobre las consignas y la censura se puede encontrar buen número de ejemplos en el libro de Sinova, Justino, La censura de prensa durante el Franquismo. Madrid, Espasa, 1989. Dicha obra adolece sin embargo, a nuestro juicio, del defecto de estar excesivamente centrada en la censura de prensa, con una escasa atención al contexto político, lo que le impide realizar un análisis suficientemente en profundidad del propio objeto tratado. 
Al control de la prensa periódica "de empresa" o privada se une la fuerza del propio grupo de Prensa del Partido, que cae en estos momentos en la potestad del Delegado Nacional de Prensa. Con ello se completaba en la prensa la acumulación del poder (que ya, como vimos, se daba con anterioridad a 1941 en el sector "propaganda") ${ }^{21}$. Han de tenerse en cuenta también la dependencia de la VSEP de la Agencia EFE (y por tanto, sus filiales CIFRA y ALFIL) y de la Escuela Oficial de Periodismo.

Pero incluso en tal estado de cosas la población española no podía permanecer hermética a las noticias llegadas de fuera y hubo canales que escaparon al filtro de la VSEP. Entre ellos -e independientemente de la circulación de publicaciones clandestinas - fue de extraordinaria importancia la escucha de las noticias de emisoras extranjeras, entre las que destacaron la BBC, la Voz de América para España y, en menor medida, Radio España Independiente (la "Pirenaica»). Todos estos canales -amplificados y en gran medida deformados en sus mensajes por el rumor- imponian a la prensa franquista la necesidad de tratar de algún modo temas que normalmente no hubiera sido de su agrado, so pena de disminuir más aún su credibilidad ${ }^{22}$.

A partir de 1942 y desde la Delegación Nacional de Prensa se trató de desarrollar lo que probablemente sea el primer intento de una percepción más o menos científica de la opinión pública, en la línea de las tendencias desarrolladas en las dos décadas precedentes en varios países occidentales ${ }^{23}$. A tal efecto existió en el seno de la DNPrensa una

${ }^{21}$ Puede llamar a confusión - como de hecho, en su momento, to hizo- que el conjunto de medios directamente en manos de Falange recibiese el nombre de Delegación Nacional de Prensa y Propaganda. Su prensa fue largamente privilegiada, con un criterio político y en modo alguno comercial. Abundan los testimonios que muestran la escasa aceptación popular de diarios como Arriba. Con algo más de 90.000 ejemplares de tirada (datos "oficiales", del Anuario de la Prensa Española de 1944), la tirada esto no es algo decisivo, pues la tirada dependia en gran medida de los cupos de papel y así, si rara era la provincia en que los años 41-45 se vendia mucho más allá de un centenar de ejemplares de Arriba, en Barcelona la tirada normal de La Vanguardia quedaba agotada por las suscripciones y algunos números se "revendían".

${ }^{22}$ De ahí que la VSEP cuidase de establecer un servicio de escuchas que recogiese noticias de emisoras extranjeras, que se tenían en cuenta a la hora de "orientar" la prensa española, tanto en el sentido de desmentir determinados bulos como en el de aprovechar los puntos débiles de las noticias y opiniones difundidas desde el extranjero. Con parte del material proveniente de esas escuchas se elaboraron boletines "confidenciales" destinados a las autoridades.

${ }^{23}$ No se trata sólo, como podría pensarse, de los países democráticos, como Francia, Inglaterra y Estados Unidos; también en la Alemania hitleriana el Régimen se preocupó de la valoración de las tendencias de la opinión y de los efectos de sus propagandas; véase 
sección de Documentación y Auscultación y un Instituto de la Opinión Pública, a cargo de Cayetano Aparicio, que trató de estudiar el estado y evolución de la opinión; los resultados no eran ajenos a unas condiciones bien difíciles - si no peligrosas-para una libre expresión de las actitudes, dificultades que alcanzaban incluso a los propios encargados de recoger esas impresiones, que dudaban en ocasiones si el mismo hecho de transmitirlas no les "manchaba" haciéndoles sospechosos de complacencia ${ }^{24}$. No es de extrañar que los resultados dejasen bastante que desear.

\section{La Delegación Nacional de Propaganda}

Frente al campo de actuación de la DNPrensa el de la DNProp. resulta mucho más heterogéneo. En él se englobaban:

- Control de todo tipo de publicaciones no periódicas, labor adscrita a una sección de Ediciones y Publicaciones que contó con un cuerpo de «lectores" (censores), el apoyo de toda una red de inspectores de la propia VSEP, del Partido (Delegación Nacional de Investigación e Información) o policiales ${ }^{25}$. Directamente relacionadas con esta sección aparecen la Editora Nacional y el Instituto Nacional del Libro (INLE), que sustituyó por entonces a las Cámaras del Libro de Madrid y Barcelona.

\footnotetext{
at respecto el muy interesante libro de Kershaw, lan, Der Hitler-mythos. Propaganda und Volksmeinung im Dritten Reich. Stuttgart, Deutsche Verlags-Anstalt, 1980 (Schriftenreihe der Vierteljahrshefte für Zeitgeschichte; 41). Sobre el caso de la Francia de Vichy, Pierre Laborie ha llevado a cabo varios estudios, entre los que destaca L'opinion publique sous Vichy. Paris, Seuil, 1990 (Coll. L'univers historique).

${ }^{24}$ Así, las reticencias de algunos delegados para transmitir a sus superiores, por ejemplo, "chistes groseros" referentes a jerarquías. Algún gobernador civil-jefe provincial del Partido montó en cólera cuando, teniendo que dar su visto bueno a un informe de la VSEP se veía criticado por un sector de la opinión, por lo que impidió enviar a Madrid dichas críticas.

${ }^{25} \mathrm{~L}$. AbelLAN, Manuel, ha publicado una amplia serie de trabajos sobre las condiciones en que debió de desarrollarse la creación literaria y la edición en el Franquismo. Destaca su Censura y creación literaria en España (1936-1976). Barcelona, Península, 1980. Abellán fue pionero en la utilización de los archivos del entonces Ministerio de Información y Turismo, cuando aún no habian sido remitidos al Archivo General de la Administración.
} 
- La cinematografía y los noticiarios filmados ${ }^{26}$, con un sistema de censura y control similar en sus grandes líneas al de los otros campos; destacó aquí la producción propia a partir de enero de 1943 de un noticiario cinematográfico, el NO-DO, de proyección exclusiva y obligatoria en todas las pantallas de España. No parece extraño que en este campo, unidas la situación politica a las condiciones técnicas de extrema precariedad de la España del momento, la influencia alemana se dejase notar por doquier. NODO tuvo desde el principio una impronta germana ${ }^{27}$. Ya con anterioridad se habían establecido fuertes lazos técnicos y políticos; el convenio hispano-alemán de cine, de 26 de abril de 1940, indicaba que "cada una de las partes contrayentes se obliga a evitar en su propio pais la producción y distribución de películas que puedan perjudicar el prestigio nacional del otro país contrayente. Ambos paises colaborarán en la forma posible a fin de impedir la distribución de tales películas en otros países" ${ }^{28}$.

- El teatro, tanto en su vertiente escrita - edición- como su realización y representación. Esto alcanzaba igualmente a los espec-

${ }^{26}$ Aunque trate una problemática mucho más amplia, sigue siendo de utitidad sobre el campo de la producción cinematográfica el libro de GuBERN, Román, La censura. Función política y ordenamiento juridico bajo el Franquismo. Barcelona, Península, 1981, que se beneficia en este caso de un conocimiento que en gran parte procede sea de la experiencia personal, sea del testimonio recogido en forma directa.

${ }^{27}$ Por convenio firmado el 20-12-1942, y por una validez de cinco años entre Joaquin Soriano (como director de NO-DO) y Fritz Tietz (como "director gerente y jefe de la sección extranjera del noticiario alemán, entidad monopolizadora de las Actualidades Alemanas") el NO-DO tuvo a su disposición toda la organización del noticiario alemán en España, que cesaría en sus actividades, "constituida por el noticiario Ufa e integrado por personal que pasará a depender de NO-DO, material de producción y de oficina, archivos de ruido y de música (...)". Reseñamos algunos de los puntos del convenio (localizado en el AGA, Alcalá de Henares): El Deutsche Wochenschau de Berlín proporcionaba además la película virgen, las noticias de Alemania y su área de influencia, pudiendo NO-DO suministrarlas a su vez a América latina y Portugal "sin que en ningún caso puedan ser utilizados, por dichos paises, con ofensa para Alemania". Los noticiarios alemanes (principalmente los exteriores) incluirian noticias de España de acuerdo con los intereses "de la propaganda española". Por parte alemana se instalaria un estudio de doblaje en Madrid "con arreglo a la técnica más moderna", asegurándose la instrucción de los técnicos de NO-DO. NO-DO, por su parte, cedía a la parte alemana sus archivos de imagen y sonido y ésta recibia la exclusiva para Europa continental (salvo Italia y su imperio). NO-DO debía reservar en las noticias exteriores «lugar preferente a las noticias de Alemania y de los paises sometidos a su influencia, especialmente reportajes de guerra, en función de su importancia desde el punto de vista europeo".

${ }^{28}$ Convenio citado, articulo $3 .^{\circ}$. Fue firmado en Berlín por el jefe del Departamento Nacional de Cinematografía del Ministerio de Gobernación (entonces Manuel Augusto García Viñolas), el presidente de la Comisión Reguladora de la Cinematografía del Ministerio de Industria y Comercio y el presidente de la Reichsfilmkammer. 
táculos de circo, variedades, etc. La VSEP controlaba directamente en Madrid como empresas propias el Teatro Español y el Teatro Escuela Lope de Rueda.

- La radio, en un control paralelo al establecido sobre la prensa, que imponía la prohibición de las improvisaciones ${ }^{29}$. Junto a las emisoras privadas (entre las que destacaba ya la Cadena SER) Radio Nacional de España era el centro de una red estatal que tomó el nombre de REDERA (Red Española de Radiodifusión) ${ }^{30}$, que además marcaba la pauta al ser sus noticiarios los únicos permitidos y de emisión obligatoria por todas las demás estaciones.

- La producción, exposición y comercialización de todo tipo de objetos "plásticos", que englobaba desde las exposiciones artísticas hasta la censura de objetos con emblemas o imágenes de personalidades del partido, del Estado, etc. La censura y eventualmente el diseño de monumentos relacionados con el partido, la guerra civil, los caídos, las personalidades del Estado...

- La producción, reproducción, ejecución en público, la venta de las reproducciones en disco, de producciones musicales, atendiendo especialmente a la censura del contenido de su letra ${ }^{31}$.

- El uso público de la palabra, sea en conferencias u otro tipo de actos públicos, actividades de la Iglesia no directamente relacionadas con el culto, etc.

Vemos así como la intervención del poder era posible en todos los escalones de la cadena de producción cultural, desde el momento en que ésta quisiera salir de lo estrictamente privado: desde las personas; los medios de producción y el propio proceso en todo momento; la distri-

${ }^{29}$ Circular 95, de 17-9-1942.

${ }^{30}$ Con el apoyo técnico de la Alemania nazi se iniciaron en aquellos años las instalaciones de Arganda.

${ }^{31}$ Pero no solamente, como muestra la campaña emprendida por la VSEP contra la música "negra". En la circular 95 de la DNProp, citada más arriba, se dice "queda terminantemente prohibido trasmitir (...) la llamada música "negra", los bailables "Swing" o cualquier otro género de composiciones cuyas letras estén en idioma extranjero, o por cualquier otro concepto puedan rozar la moral pública más elemental o el buen gusto". Lo referente a la música "negra" parece copia voluntaria o no de similares iniciativas en la Alemania nazi. Vid. al respecto, Wulf, Joseph, Musik im Dritten Reich. Eine Dokumentation. Frankfurt, Ullstein, 1983, especialmente el cap. 4. 
bución o representación, hasta el consumo, en todo momento (o más bien en todos los momentos) podían aparecer los nuevos inquisidores.

Otras secciones u organismos "autónomos" tenían funciones más especificas, como es el caso del CIAS (Comité de Investigación y Actuación Social), en realidad -en estos años - una célula de enlace con el Antikomintern de Berlín, a fin de coordinar la propaganda anticomunista de la Alemania nazi, relanzada con renovado vigor tras el ataque a la URSS en junio de 1941, con la de la VSEP. Igualmente existió la Asociación Hispano-Germana, sustentada con fondos de la VSEP, y que tuvo también un carácter de organismo propagandistico en favor de la Alemania hitleriana en el campo cultural y económico.

El personal de la VSEP recogía en buena parte el de los servicios que la preceden pero con una ampliación considerable en su número. Para los escalones provinciales supuso este momento la asignación fija de salarios (cosa hasta entonces nada clara, pues muchos de los delegados provinciales de propaganda anteriores carecian de asignación alguna). Sin contar con el personal de la prensa y la radio del partido (que podría superar, por sí solo, las mil personas) la VSEP pudo contar con más de 1.500 personas hasta el escalón provincial. Las delegaciones comarcales y locales normalmente, cuando existieron, se ocupaban sin una remuneración específica (salvo excepciones, como es el caso de la provincia de Barcelona) y muchas veces se acumulaban a otros cargos del Partido ${ }^{32}$. En cuanto a los agregados de prensa de las embajadas, estaban asimilados a ciertos efectos a los delegados provinciales de la VSEP, pero su dependencia de Asuntos Exteriores hace más problemático que los podamos considerar propiamente personal de ésta.

Es necesario atender a los equipos que ocuparon los escalones más altos de la VSEP. Para todo el período, dos personas permanecen sin interrupciones en sus cargos: el vicesecretario (Gabriel Arias Salgado) y el delegado nacional de Prensa (Juan Aparicio López). La Delegación Nacional de Propaganda estuvo ocupada en su primer periodo por el catedrático de Derecho, Manuel Torres López ${ }^{33}$, y más tarde por David

32 Asi como se podia ser director de un periódico de Falange en una provincia y censor de la prensa de la misma, no era acumulable el primer cargo con el de delegado provincial de la VSEP.

${ }^{33} \mathrm{Se}$ da la circunstancia de que los tres primeros (Arias, Aparicio y Torres López) habian coincidido ocupando cargos en la Salamanca de la Guerra y la inmediata posguerra: Arias como Gobernador, Aparicio como Director de La Gaceta Regional y Torres López como Alcalde. Tanto Aparicio como Torres habian trabajado en la Delegación de Estado para Prensa y Propaganda. Torres había sido, además, delegado local de Propaganda en la época del Servicio Nacional de Propaganda. 
Jato, permaneciendo con ambos Patricio González de Canales, como secretario nacional. Sería interesante hablar también de los responsables de las Secciones (algunas, no lo olvidemos, teóricamente destinadas a ser Delegaciones Nacionales), pero aqui la cantidad de nombres se multiplica y los cambios son muy numerosos, existiendo, además muchas situaciones "de hecho". Destacaremos únicamente a varios, sin pretensión de exhaustividad: Juan Beneyto Pérez (que elaboró una síntesis de las normas jurídicas sobre las competencias de la VSEP ${ }^{34}$ ) y responsable, en distintos momentos, de censura de libros y de la coordinación con Ministerios; Federico Sopeña y Daniel Buhigas, en Propaganda Oral y Musical; Juan Cabanas (Plástica); Luis Gómez Collado, en Organización de actos públicos; Dario Fernández Flórez, en Ediciones; Antonio Fraguas y Joaquin Argamasilla, en Cine y Teatro; Santiago Jaráiz y Antonio de Luna, en Radio; José Rus, en Asuntos Generales. En Prensa, citaremos a Ventura Asensio, en Censura; Raúl Sánchez Nogueras y Luis Ayerbe, en Asuntos Generales; Antonio Valencia, como secretario nacional; Emilio Romero, que había sido director del diario Información de Alicante (diario del partido) ocupó un cargo en el entorno del delegado nacional, Juan Aparicio, al menos en 1945.

\section{CAUDILLISMO, FALANGISMO Y UNA "GERMANOFILIA» VARIABLE. UN DETERMINADO MODELO DE CULTURA}

Vamos a referirnos a continuación a los mensajes transmitidos por la VSEP, o dicho de otro modo: lo que la Falange de Arrese dijo a través de "su Ministerio" de la propaganda. Consideramos que el estudio de esta cuestión "desde dentro", con apoyo en las fuentes generadas por el propio aparato, presenta aspectos que no serian aprehensibles en la misma medida con el simple vaciado de la prensa de la época, pues en ocasiones la VSEP ocultó expresamente la procedencia de parte de su propaganda ${ }^{35}$. Asimismo, la propaganda radiofónica ha resultado normal-

${ }^{34}$ Régimen juridico de Prensa y Propaganda, Madrid, Instituto Editorial Reus, 1944

${ }_{35}$ Por poner algún ejemplo, parte de la propaganda impresa de la VSEP - en ocasiones por lo "comprometedor" de su contenido, otras veces porque se consideraba más efectiva si no aparecia como "oficial»- aparecia como de Ediciones Toledo. Así se publicó a principios de 1942 Cautivos de la libertad, del antisemita y antidemócrata norteamericano CARROL, Michael. Hay multitud de casos de propaganda "Oculta" documentados, folletos hechos para su distribución por las iglesias, carteles ferozmente antinorteamericanos, etc. Existieron proyectos de la VSEP -desconocemos si llevados o no a término- para publicar obras de propaganda subliminal como novelas rosa o policiacas (sic). 
mente más difícil de analizar y sobre ella aportan las fuentes de la VSEP datos interesantes.

Destaca como constante la "exaltación del Caudillo" Franco, exaltación activa y pasiva que abarca la palabra y la imagen ${ }^{36}$, que no por fanática deja de cumplir una función de interés para el aparato de Falange, siendo una cuestión menor su sinceridad o insinceridad ${ }^{37}$ :

- Legitima ante Franco el resto del discurso falangista.

- Afianza la posición de Falange en el seno del Régimen, pues mediante la exaltación de Franco (que reúne la doble condición de Jefe Nacional del Partido y Generalísimo de los Ejércitos) se promociona a la propia Falange, especialmente en un contexto en que la cúpula militar se permite plantear condiciones respecto al rumbo político que tomar.

- Responde a una conciencia práctica a efectos de lograr un consenso en favor del Régimen; a ese respecto Franco podía funcionar como denominador común para unos sectores heterogéneos de la Opinión (de los que se excluye, claro está, a la mayor parte de los vencidos de la Guerra Civil).

Hay igualmente un fuerte voluntad de afirmar "la presencia del Partido" en todos los aspectos de la vida española ${ }^{38}$, resaltando cómo es

${ }^{36}$ Así, la VSEP tenia buen cuidado de que sólo determinadas fotografías "del Caudillo" pudieran aparecer en la prensa.

${ }_{37}$ Resulta chocante la escasa información que sobre esta época presentan algunos escritos sobre los sectores falangistas "de oposición" durante el Franquismo. Se habla por ejemplo de falangistas "conspiradores" incluso hasta el punto de proyectar un atentado contra la vida de Franco, como podría ser el caso de Patricio González de Canales (Vid. Romero Cuesta, Armando, Objetivo: matar a Franco. La Falange contra el Caudillo. Madrid, Ediciones 99, 1976, pero se olvida que a la vez este mismo actuaba como uno de los máximos responsables de la VSEP (secretario nacional de Propaganda) y desde allí era uno de los impulsores de la imagen del propio Franco. Señalemos también que en una Antología de propaganda clandestina falangista como es la de OnRUBIA, Javier, Historia de la oposición falangista al régimen de Franco en sus documentos. Madrid, Libreria Fragua, 1989) no aparece ningún ejemplo correspondiente a los años 1941-45. Apuntamos rápidamente dos caracteristicas de la inmensa mayoría del material correspondiente a esos años: apoyan (o bien soslayan) a Franco, pero rara vez manifiestan una abierta oposición; casi unánimemente reprochan al régimen la supuesta tibieza en su germanofilia. Sin dudar del esfuerzo que esa antología supone no iriamos demasiado lejos pensando que esas caracteristicas desentonaban en una imagen ideal de esa Falange "de oposición" o en los márgenes del Régimen.

${ }_{38}$ Aunque no parece que la individualidad concreta del secretario general Arrese fuera objeto de una exaltación personal sí se trató evidentemente de ponerla a cubierto de posibles criticas o mofas. De ahi el humorismo involuntario de esta consigna para la censura de la prensa de 5 de septiembre de 1941: "Queda prohibido que en los titulares de los periódicos figure el pelotari Arrese II. Que Abizanda llame mañana a los periódicos de Madrid para decirles que en lo sucesivo se abstengan de dar esos títulos". 
Falange lo que añade un aspecto innovador al Régimen como garante de su vertiente «social». La propaganda falangista en general añadia a este aspecto la voluntad de expansión imperial (en el Norte de África), tema que tras el desembarco aliado en África del Norte en noviembre de 1942 fue rápidamente soslayado, ante las presiones del Ministerio de Asuntos Exteriores ${ }^{39}$.

El conflicto con otras fuerzas también sustento del Régimen era siempre algo más que una posibilidad y la VSEP tendió siempre a limar los roces, a negar su existencia mediante una propaganda que, ahí sí, fue bastante cauta: caso de las campañas llevadas a cabo en 1942 respecto a la "unidad Ejército-Falange" o todo lo relativo a la reiteración de la catolicidad de Falange y el Régimen; de ahí que también a efectos de censura lo directamente relacionado con Ejército o Iglesia tuviera- además de la censura de la VSEP - que pasar una criba suplementaria a cargo de estas instituciones ${ }^{40}$.

Más sujeto a cambios debido a la coyuntura, y -con ser bastante claro- un aspecto más complejo, destaca como punto importante la identificación con los fascismos europeos, especialmente con la Alemania

${ }^{39}$ La tensión entre el Ministerio de Asuntos Exteriores y la VSEP en estos momentos está bien reflejada en los documentos: una nota ("reservada y confidencial") que firma Manuel Torres López como consejero nacional en funciones de delegado nacional de Propaganda y dirigida el 9 de noviembre de 1942 a Arias Salgado (como responsable, este último, de la VSEP) dice:

\begin{abstract}
"Creo mi deber comunicarte que la nota del Ministerio de Asuntos Exteriores, con motivo de los sucesos actuales en el Norte del África Francesa, ha sido acogida por la opinión, principalmente coincidente con la ideología del Estado y del Movimiento, con verdadero disgusto y produciendo gran desconcierto, mientras que la opinión anglófila y de los [ilegibles] «enemigos" o "elementos" ¿?] rojos del país, se regocija con ello, haciendo público alarde del éxito que representa.
\end{abstract}

Te hago esta consideración por considerar deber mio, como delegado nacional de Propaganda, informar de estos estados de opinión a tu jerarquia y a los superiores si lo estimas convenientes.

Por Dios, España y su Revolución Nacional-Sindicalista».

ejemplo son igualmente los artículos que la VSEP intentó enviar a los pocos días del desembarco aliado en África del Norte para su emisión obligatoria a todas las radios de España («Postura espiritual», 14 de noviembre de 1942) y otros de similar orientación, en los que aparece la indicación "prohibido por Asuntos Exteriores".

${ }_{40} \mathrm{El}$ caso más claro y el más reglamentado es del cine, en el que la Junta Superior y la Comisión Nacional de Censura Cinematográfica suponen una instancia que venía a aliviar a la VSEP de posibles conflictos en cuanto a la autorización de contenidos en el medio probablamente más popular y de mayor impacto de la época. En ellas estaban representadas la Jerarquía eclasiástica y el Ejército. 
nazi y la Italia fascista, una tendencia que los coetáneos resumian unánimemente como "germanofilia". Se concreta en las facilidades dadas a la propaganda nazi para su actuación en España, los lazos establecidos con los organismos alemanes de la propaganda y el sentido abiertamente sesgado que se impone a la Prensa española hasta una época asombrosamente tardia ${ }^{41}$, lo que sólo se explica por la inercia que provocó la actitud de tiempos anteriores.

La "germanofilia" - para ser más exactos: el pronazismo- de los sectores dominantes en la VSEP tuvo como contrapeso las presiones ejercidas desde el Ministerio de Asuntos Exteriores en favor de una actitud más moderada en los mensajes de la prensa y la propaganda. Estas presiones no se circunscriben al período de Jordana, sino que datan ya del paso de Serrano Suñer por ese Ministerio ${ }^{42}$.

Una obra publicada en su primera forma en los años del aislamiento ${ }^{43}$ y más tarde y por «iniciativa oficial» ${ }^{44}$ como Viraje político español en la Segunda Guerra Mundial puede ilustrar algunos aspectos de la dificil y tardía adaptación que la VSEP hizo en el momento en que el declive del Eje iba siendo cada vez más claro. Pero sólo resulta ilustrativa a condición de tener en cuenta tanto lo que calla como lo que dice, pues recoge únicamente las órdenes que a partir de noviembre de 1942 fueron intentando dar a la Prensa un rumbo más acorde con los tiempos, sin referirse a las prácticas que las contradijeron o que sumieron

${ }^{41}$ Están por hacer aún los trabajadores que de un modo sistemático estudien la visión que de la guerra Mundial dio la prensa española. El libro de Justino Sinova, ya citado, aporta interesantes ejemplos, pero en modo alguno una visión global. Exite el trabajo de Garcia Alix. Conrado, La Prensa española ante la segunda guerra mundial. Madrid, Editora Nacional, 1974) a todas luces insuficiente por lo escasamente crítico (declara centrarse en la revista Mundo, por su «mayor objetividad", lo que no deja de ser una curiosa razón para seleccionar las fuentes para un estudio con el título arriba citado). Debemos referirnos a una investigación aún en curso y bastante centrada en este punto, la de Carmen Campuzano (del departamento de Historia Contemporánea de la UNED).

${ }_{42}$ En Garriga, Ramón, La España de Franco, se reflejan numerosos ejemplos de las tensiones entre Asuntos Exteriores y la VSEP; El libro de Justino SINOVA ilustra tambièn esta cuestión, no sin caer en el tópico erróneo de un cambio radical de las tendencias de la prensa tras la caída de Serrano, afirmación que, por otro lado, desmienten los ejemplos aportados a continuación por el citado autor.

${ }^{43}$ Rio Cisnerios, Agustín del, España rumbo a la posguerra. La paz española de Franco, 1947 y Política internacional de España. El caso español en la ONU y en el mundo, 1945-1946, 1946.

"44 La referencia a la “iniciativa oficial» procede del expediente de censura de la obra (en su primera edición, 1965) en el AGA, Sección Cultura, donde se alude a ella para indicar que es motivo por el que no procede sea censurada. 
a la opinión en el confusión ${ }^{45}$. Patético y cómico resulta el testimonio de un Delegado de provincias que en 1943, transmite a sus superiores la confusión reinante en ciertos ambientes, ante las contradicciones que se perciben:

“El jefe Local de Pedro Muñoz [...] me decia hace unos días que le determinase cuál creía debía ser su postura. "Si le rompo la cabeza a toda esa gente que se ha vuelto anglófila, si los meto en la cárcel a la primera manifestación que hagan, o si por el contrario les tiendo la mano y me hago yo uno de ellos" $"{ }^{46}$.

Independientemente de los contenidos de la Prensa, la propaganda hitleriana gozaba de una tolerancia que sólo tal vez a partir de finales de 1944 fuera otorgada a la aliada ${ }^{47}$.

En estos años hubo una evolución perceptible en cuanto a la presencia y peso relativo de los temas de la propaganda: la insistencia en las reivindicaciones españolas de expansión en el norte de África ocupa un lugar importante al principio; tras el ataque alemán a la URSS se exalta la hermandad de armas con Alemania en la lucha contra el comunismo. La propaganda anticomunista tomó nueva fuerza cuando el signo de la guerra pareció cambiar y fue ocupando cada vez un lugar más importante ${ }^{48}$, relacionándose ya en 1942 y los años siguientes con la posibilidad de un peligro interior si no se cerraban filas en torno a Franco, reprochándose la ceguera de sectores de la burguesía que desearían la

${ }^{45}$ Agustín del Río Cisneros, estuvo en estrecha relación con Asuntos Exteriores a partir de la Etapa Jordana y desde la Delegación Nacional de Prensa (donde se ocupa de las colaboraciones para la prensa del Partido) inició el envio de consignas paulatinamente más "neutralistas" a la prensa nacional. Ello sólo se hizo son sumas dificultades, con la oposición abierta en ocasiones de Arrese y amenazas por parte de los sectores más germanófilos. Del Río se iría más tarde consagrando como compilador y exegeta casi oficial de las obras de José Antonio. Al testimonio oral del propio Agustín del Río debemos muchos datos sobre su actuación en aquellos años.

${ }^{46}$ De un informe del delegado provincial de Ciudad Real. Octubre de 1943. AGA-C, 732 .

${ }^{47}$ Como un ejemplo entre tantos: sólo a finales de 1944 aparece la revista aliada de propaganda Victory en los quioscos, mientras la alemana Signal nunca habia dejado de estar presente.

${ }^{48}$ Vid., Circular 152 de la DNProp. de 19 de octubre de 1943. Reservada. A los Delegados Provinciales de la VSEP, sobre campañas anticomunistas. Todas las emisoras de España debían organizar una serie de conferencias anticomunistas (evitando señalar la procedencia de la iniciativa). Una de ellas debía estar a cargo de un voluntario de la División Azul. 
victoria aliada. Una consigna a los directores de periódicos de Madrid fechada el 23 de octubre de 1942 resume bastante bien esto:

“Ese periódico realizará una campaña a partir del dia de mañana y hasta el 28 inclusive de acuerdo con las siguientes instrucciones:

Todo ataque a la integridad del movimiento y su caudillo, es cumplir

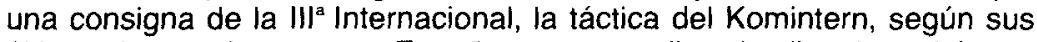
últimas instrucciones para España no es predicar la dictadura del proletariado o la lucha de clases, sino "socavar" y "desunir" a los Estados que han roto sus relaciones con la URSS aireando y propagando las "pequeñas razones" que siempre tienen las oposiciones frente a los gobiernos totalitarios. Hoy son, pues, "comunistas" porque obedecen una consigna de Moscú, los "monárquicos", "los liberales", "los estraperlistas", los "neutros"... en una palabra, todos los que con sus criticas, omisiones o actos favorecen las intenciones del Mando comunista".

Aludiremos al modelo de "cultura española» promovido desde la VSEP, del que aquí sólo se podrían apuntar algunos trazos: cultura española en la concepción "imperial» de Falange, donde estaba fuera de discusión el catolicismo conservador, asi como el predominio de la lengua castellana. Ante las influencias lingüísticas que se desviasen "de la pura línea nacional" se adoptó una postura defensiva, prohibiéndose los vocablos extranjeros en multitud de ámbitos ${ }^{49}$. Respecto a lo que el lenguaje oficial llamaba «dialectos regionales» (en realidad las lenguas catalana, vasca, etc.) la desconfianza era abierta y la actitud se podría resumir en la tolerancia reducida a los casos en que se subrayase su carácter "folclórico", poniéndose todas las trabas posibles al uso "público» de esas lenguas en la radio, la canción, la edición... e incluso la práctica religiosa ${ }^{50}$.

${ }^{49}$ Existieron normas sobre la denominación de establecimientos comerciales, como la del 16 de mayo del 40; prohibiciones de actuaciones y canciones en locales públicos y radio en lenguas extranjeras, etc.

${ }^{50}$ Respecto a las dificultades habidas por parte del clero catalán respecto al uso de la propia lengua es de sumo interés la comunicación de SOBERANAS, Amadeu-J., "Repressió lingüistica a l'Esglesia a la immediata postguerra (1939-1940)", en Actes del Setè Col-loqui internacional de llengua i literatura catalanes, s. 1.: Publicacions de l'Abadia de Montserrat, 1986, págs. 703-721; la Tesis de María Josepa Gallofré (presentada en la Universidad Autónoma de Barcelona en 1990) sobre la Edición catalana y la censura franquista supone una importante ampliación del conocimiento sobre ese aspecto de la presión sufrida por las culturas no castellanas como tales. 


\section{EL CAMBIO DE 1945-1946. DE ANTIDEMOCRÁTICOS E IMPERIALES A CATOLLICOS Y “OCCIDENTALES»}

Aunque la derrota del Eje no era posibilidad considerada en el ambiente político en que se creó la VSEP, ésta se vio -o fue- obligada a ir rectificando - siempre muy tardiamente - el rumbo a medida que la derrota del Eje iba siendo más evidente ${ }^{51}$. Todavía tocaria en buena medida a la VSEP intentar convencer a los españoles de que tal fin de la guerra mundial no implicaba el del régimen de Franco ni el de la posición privilegiada de Falange. Si en 1943 y tras la caída de Mussolini se prohibía llamar Partido a Falange ${ }^{52}$, en 1945 Arrese trataba de demostrar como ésta no tenía ningún componente totalitario, lo que no dejaba de ser un detalle cuando las tropas soviéticas se acercaban a Berlín.

La vida de la VSEP como tal termina con su adscripción en el verano de 1945 - ahora como Subsecretaria de Educación Popular- al Ministerio de Educación Nacional ${ }^{53}$, siendo entonces Ibáñez Martín titular de este último. La alusión a los motivos de tal cambio en el Boletín Oficial sorprende por su aparente ingenuidad al indicar como razón del cambio el que estas actividades están directamente relacionadas con la Educación. Meses después, en enero de 1946, tuvo lugar la llegada de un equipo de "católicos colaboracionistas" a estos cargos ${ }^{54}$. La primera circular tras el cambio real de equipo dirigida a los Delegados Provinciales data del 30 de enero de 1946 y está firmada por el nuevo secretario general de Propaganda, G. Escribano. Sus términos son bien reveladores:

51 Lo que muchos tardaron en aceptar. Abundan los informes de delegados provinciales que todavía a finales de 1944 confian en un fin de la Guerra favorable a Alemania, o al menos en una «honrosa paz en tablas".

${ }_{52}$ Existe un telegrama dirigido a todos los delegados provinciales por la DNProp. el 16 de diciembre de 1943 donde se dice "(...) he acordado prohibir la palabra partido cuando se refiera a la organización de FET y de las JONS". Se ordenaba igualmente hablar de movimiento, Falange u Organización.

53 Sobre el periodo que sigue, vid. TuSELL, Javier, Franco y los católicos. La política interior española entre 1945 y 1957. Madrid, Alianza, 1984, donde existen bastantes referencias al equipo que encabezó Ortiz Muños como subsecretario. En la pág. 94 sitúa Tusell en la reunión del Consejo de Ministros de 21 y 23 de julio de 1945 la decisión de realizar la transformación de la VSEP, cuya importancia Franco parecía minimizar, a la vez que indicaba que, por el momento no se nombrase al sucesor de Arias Salgado (pág. 95).

54 Ortiz Muñoz, como subsecretario de Educación Popular, Tomás Cerro, como director general de prensa y Pedro Rocamora como director general de Propaganda. Además se unirán las nuevas direcciones generales de Radio (Alfredo Guijarro) y Cinematografía y Teatro (G. García de la Espina). 
(...) Es deseo del limo. director general [de Propaganda, Pedro Rocamora] que las Delegaciones Provinciales se abstengan de ejecutar propagandas no autorizadas expresamente por esta secretaría con el visto bueno del director.

De momento le subrayo que la más eficaz es la de carácter directo. Todo debe cifrarse, por ahora, en exaltar la obra realizada por nuestro glorioso caudillo y su gobierno en los diversos órdenes de la vida nacional: obras públicas, social, cultural, sanitaria, de reconstrucción, marina mercante, etc. Para su práctica, recibierá en su día las oportunas normas. $(. . .)^{55}$.

Ahora brillaba por su ausencia cualquier alusión a Falange. Ésta conservó, sin embargo, el control de su propia prensa, al sustraerse ésta última de la autoridad de la nueva subsecretaria e incluso permitirse el polemizar con los nuevos poderes en materia de prensa ${ }^{56}$. $Y$ en cualquier caso la historia del equipo Arias Salgado-Juan Aparicio no terminaba, pues en 1951 se produce en parte su vuelta, con la creación del Ministerio de Información y Turismo, que supuso en alguna medida su revancha.

\section{CONCLUSIONES: ¿UNAS TENDENCIAS POCO SIGNIFICATIVAS?}

En 1939 un delegado provincial de Propaganda marcadamente falangista (que fue más tarde delegado con la VSEP), cuando ésta estaba regida por Dionisio Ridruejo, acababa un informe en que hablaba de las dificultades para el adoctrinamiento de la masa obrera en sentido falangista, de las pésimas condiciones de vida en su provincia, etc., con estas palabras: "frente a todo esto, no caben propagandas".

Ésto nos puede ilustrar sobre algunas de las limitaciones que la labor de un aparato como la VSEP se pudo encontrar: ni todos los resortes de la política estaban en manos de Falange, ni la propaganda era un arma infalible, capaz de pasar por encima de todas las barreras, por encima de la realidad que las gentes percibian.

Entre los campos de actuación que a Falange se le encomendaron, probablemente fuera éste uno de aquellos en que más posibilidades tuvo

${ }^{55}$ Circular número 1-1946. AGA-C-IT-2359.

${ }^{56}$ Vid., por ejemplo, TUSELL, Javier, op. cit., pág. 195-196. 
de actuar de acuerdo con sus propias convicciones e intereses de grupo. Pero no parece contarse precisamente entre los logros de la VSEP el afianzar la orientación falangista del régimen. ¿Contribuyó, al menos al afianzamiento de éste? Cabe preguntarse si el consenso que pudiera existir por parte de un sector de la población no se consiguió en buena parte al margen de los esfuerzos de Falange y en buena medida a pesar de ella, que, habiendo perdido la apuesta por la victoria de las armas del Eje (estamos pensando en concreto en los años de la posguerra mundial), no quedaba especialmente bien parada para aumentar su cuota de poder. A la postre, Franco - paradójicamente - si saldría beneficiado de esa imagen de Falange, pues ello le permitia - aunque fuera más bien a posteriori- ocupar un papel de ponderación y astucia, capaz de evitar la aventura bélica en propio suelo.

Hemos tratado de mostrar cómo entre los años 41 y 45 se dio la más intensa tentativa por parte del Régimen de Franco de controlar todos los canales de expresión; intentamos también presentar en rápido esquema los mensajes que por ellos se difundian. En este empeño mostraba el Régimen una inequívoca voluntad de profundización y permanencia de su control sobre la opinión pública, sea por la movilización o por el logro de la simple aquiescencia. Es al Partido a quien compete esa tarea y sólo tras la derrota del Eje a él se le arrebata el control de la mayor parte de las estructuras a esos fines destinadas.

Cuando se establecen periodizaciones del Régimen franquista se puede caer en la tendencia a formar con todas las fases un continuum en que el resultado final -el franquismo de los años sesenta y setentano deja de estar presente en alguna manera en el del coetáneo de la Segunda Guerra Mundial; o, dicho de otro modo: existe una tendencia a justificar determinadas características del primer franquismo porque éstas se adaptaron y corrigieron de acuerdo con las circunstancias sucesivas. Las tendencias totalitarias (encarnadas en organismos como el que aquí se analizaba) o la proclividad al nazi-fascismo europeo que acabó derrotado en la guerra acabaron corrigiéndose paulatinamente y en algunas imágenes extremas el Franco de 1941 no sería sino precursor y artífice voluntario de la España de la transición ${ }^{57}$.

57 Un ejemplo de ese «teleologismo justificador": el articulo del general Ramón Salas Larrazábal aparecido hace tiempo en las páginas de esta misma revista (“La División Azul», en Espacio, Tiempo y Forma, Serie V, núm. 2, págs. 227-239) y que supone una bastante explicita ( $y$ entusiasta) reivindicación de aquella empresa (a la postre beneficiosa para España, según dicho autor, que habla de "epopeya", de "gesta", de "romanticismo" de aquella acción). Se impone preguntar si en junio del 41 era ya sabido por quienes enviaron 
Es necesario que se estudien en profundidad aspectos como el que aqui se ha tratado, que pueden mostrar cómo el Franquismo poseyó en determinados momentos potencialidades $-y$ la voluntad - para avanzar hacia un modelo de totalitarismo extremo ${ }^{58}$. Y el control de toda expresión pública de pensamiento no es precisamente un aspecto secundario. Está por demostrar que fuera algo distinto de la derrota del Eje en la Segunda Guerra Mundial lo que corrigió esas tendencias, por lo que resutaría bien negativo acudir una vez más a una visión teleológica (y justificadora) de la historia del Franquismo, al que se vendría a atribuir como virtud lo que la necesidad le impuso para asegurar su superviven. cia.

a la División Azul el curso que tomarian los acontecimientos; todo parece apuntar a lo contrario.

${ }_{58}$ Para estos años todo parece apuntar al funcionamiento de un cierto equilibrio en que Falange no cuestionaba el control de la Iglesia de ciertas esferas en la medida en que las suyas fueran respetadas por la Iglesia. Si hay muestras de tensiones no parece ser lo definitorio del momento. 